\title{
HIV: „Make (+) More Positive"-Kampagne nutzt Social Media
}

- Das Healthcare- und Diagnostik-Unternehmen Alere und die internationale NonProfit-Organisation PSI (Population Services International) arbeiten seit Ende letzten Jahres zusammen. Die Kooperation soll zeigen, dass Social Media helfen kann, Leben zu retten. Als Teil der "Make (+) More Positive"Kampagne, die das Bewusstsein für HIV stärken und vom Virus betroffenen Menschen Optimismus geben soll, spendet Alere für jeden "Gefällt mir"-Klick auf Facebook, jeden „Follower" auf Twitter und jedes gepostete Kunstwerk auf den Social-Media-Seiten der Kampagne einen HIV-Test an PSI - mit dem Ziel, bis zu 1 Million Tests zu spenden.

„Der HIV-Test ist ein einfaches und verlässliches Werkzeug, um den HIV-Status zu bestimmen und im Falle eines positiven Ergebnisses ein wichtiger Ansporn, für eine geeignete Behandlung zu sorgen und auch den Partner zu ermutigen, den Test durchführen zu lassen“, erklärt Karl Hofmann, PSI-Präsident und CEO. „Wir freuen uns, dass wir uns an dieser innovativen Kampagne von Alere beteiligen und auf diese Weise helfen, den Zugang zu HIV-Tests und -Therapie auf globaler Ebene zu beschleunigen".

Mit ihrem Start im Juli 2011 auf der Internationalen AIDS-Society (IAS)-Conference in Rom hat die Alere-Kampagne „Make (+) More
Positive" eine Community ins Leben gerufen, in der sich Menschen, die von HIV direkt oder indirekt betroffen sind, sowie Künstler, Aktivisten und Gesundheitsversorger engagieren. Bereits mehr als 1.000 Kunstwerke wurden geschaffen, die auf www.morepositive. com und facebook.com/morepositive zu sehen sind.

Allein im letzten Jahr hat PSI mehr als 1,8 Millionen Männer, Frauen und Jugendliche in 26 Ländern in Afrika, Asien, Lateinamerika und der Karibik mit HIV-Tests und umfassender Beratung versorgt. Ziel der AlereSpendenkampagne ist es, solche wichtigen Programme weiter auszubauen, damit künftig mehr Menschen ihren HIV-Status kennen und einen verbesserten Zugang zu den entsprechenden Behandlungsmöglichkeiten erhalten.

Mit dem Alere Determine ${ }^{\mathrm{TM}} \mathrm{HIV}$ 1/2 Ag/Ab Combo Test kann HIV bereits wenige Tage nach einer Infektion nachgewiesen werden. Zudem bietet Alere mit dem Alere ${ }^{\mathrm{TM}}$ CD4 Analyzer Medizinern schnelle CD4-Ergebnisse und ermöglicht so die zeitnahe Initiierung von antiretroviraler Therapie und zuverlässigem Patienten-Monitoring.

Nach Informationen von

Alere, Köln

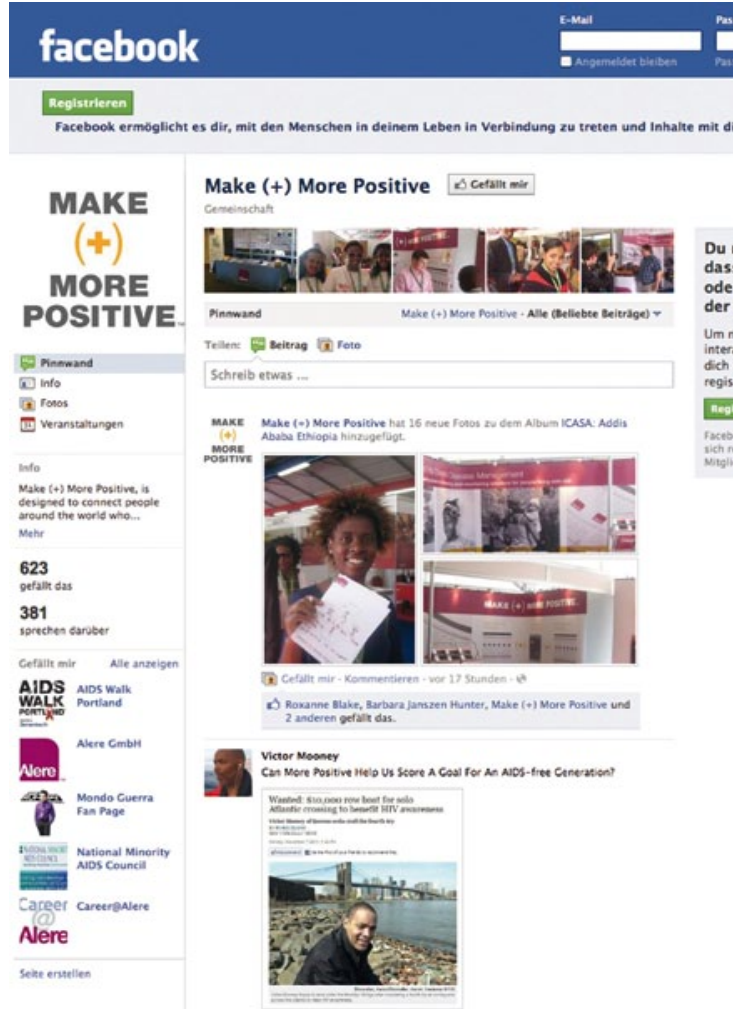

Mehr erreichen: Für eine bessere Versorgung setzt die „Make (+) More Positive"-Kampagne auch auf den Austausch via Social Media.

\section{IQWiG sieht beträchtlichen Zusatznutzen von Abirateronacetat}

— Das Institut für Qualität und Wirtschaftlichkeit im Gesundheitswesen (IQWiG) hat seine Nutzenbewertung für Zytiga ${ }^{\circledR}$ (Abirateronacetat) im Rahmen des Arzneimittelmarktneuordnungs-Gesetz (AMNOG) vorgelegt. Dieses Medikament ist in Kombination mit Prednison oder Prednisolon bei Patienten mit metastasiertem kastrationsresistentem Prostatakarzinom (mCRPC) nach Versagen einer Docetaxel-haltigen Chemotherapie zugelassen. Das IQWiG zieht in seinem Gutachten das Fazit, dass es Hinweise auf einen beträchtlichen Zusatznutzen von Zytiga ${ }^{\circledR}$ für solche Patienten gibt, für die eine erneute Therapie mit Docetaxel nicht infrage kommt, was etwa $75 \%$ der rund 7.000 Patienten mit $\mathrm{mCRPC}$ in Deutschland betrifft. Der Zusatznutzen wird für die Endpunkte Mortalität und Morbidität bestätigt. Der Zusatznutzen der
Therapie mit Zytiga ${ }^{\oplus}$ für Patienten, die für eine weitere Chemotherapie infrage kämen, wurde vom IQWiG als nicht belegt eingestuft. "Zytiga ${ }^{\circledR}$ trägt dazu bei, eine Behandlungslücke für Patienten zu schließen, für die es bisher kaum oder keine Therapiealternativen mehr gab. Wir freuen uns darüber, dass das IQWiG diesen Behandlungsfortschritt für Patienten mit metastasierendem kastrationsresistentem Prostatakarzinom auch als solche anerkennt. Mit dem Bewertungsprozess betreten wir gemeinsam mit anderen Beteiligten Neuland. Generell sehen wir in der Nutzenbewertung Herausforderung und Chance zugleich, wenn sie fair und transparent durchgeführt wird." so Dr. Ina Rudolph, Mitglied der Geschäftsführung von JanssenCilag. Abweichend von der IQWiG-Bewertung ist Janssen der Meinung, dass auch bei solchen Patienten, die formal für eine erneute Therapie mit Docetaxel geeignet sind, ein beträchtlicher Zusatznutzen von Zytiga ${ }^{\circledR}$ vorhanden ist. Diese Ansicht unterstützen auch Experten.

Den endgültigen Beschluss über den Medizinischen Zusatznutzen von Zytiga ${ }^{\circledR}$ fasst der Gemeinsame Bundesausschuss auf Grundlage der IQWiG-Bewertung, des Nutzendossiers des Herstellers sowie der eingegangenen Stellungnahmen bis Ende März. Basierend darauf beginnen im Anschluss die Preisverhandlungen zwischen dem Spitzenverband Bund der Krankenkassen und Janssen-Cilag.

Nach Informationen von

Janssen-Cilag, Neuss 